\title{
Analysis on the Awareness of Non-Communicable Disorders and its Prevention through Sports and Fitness Program among High School Students of Mekelle
}

\author{
Somsankar Mukherjee*, Hasrani SS and Saini RC \\ ${ }^{1}$ University of Natural and Computational Sciences, Mekelle, Tigray, Ethiopia \\ "Corresponding author: Somsankar Mukherjee, University of Natural and Computational Sciences, Mekelle, Tigray, Ethiopia, E-mail: \\ somsankar.mukherjee@gmail.com
}

Received date: June 7, 2016; Accepted date: June 16, 2016; Published date: June 30, 2016

Copyright: (02016 Mukherjee S, et al. This is an open-access article distributed under the terms of the Creative Commons Attribution License; which permits unrestricted use; distribution; and reproduction in any medium; provided the original author and source are credited.

\begin{abstract}
Fitness is the only key to lead a fabulous healthy life-style. With healthy and dynamic life one can not only enjoy the life time but be useful for one's society. It is known that unhealthy person is considered as burden on the family as well as on the society. It has been noted that NCD is responsible for $30 \%$ of deaths in Ethiopia in 2014 . It is also estimated by WHO-Ethiopia that $9 \%$ of males and $25 \%$ of females, whereas $11 \%$ of rural and $20 \%$ of urban population have insufficient levels of physical activity. Based on above statistics, researchers tried to find out the problems about the awareness of NCD and its preventive measures by physical activities. The researchers targeted randomly five schools from different parts of Mekelle city to find out the level of awareness about NCD and effectiveness of sports to escalate this awareness. The data we received from 356 high school students (209 boys and 147 girls) is very much surprising. As per the their view sports is considered as recreation only, but have very less idea about its benefits, where as they are not aware of causes and consequences of NCD. Moreover, we found that $47 \%$ of students ( $32 \%$ of girls and $51 \%$ of boys) are willing to play out door games, which represents laziness among the young generation and a warning sign for progression of NCD among upcoming generation of Mekelle, may be true for the whole of Ethiopia. Similarly, we found several such factors on related issues and have been discussed further. We have used non-parametric - chi square statics to find the chance of error. To stop or prevent such problems we suggest that awareness on Non Communicable Disease, its problem and its prevention is best through sharing of knowledge. Even we like to suggest that every education sectors should consider seriously introducing about sports and physical fitness curriculum just like other professional subjects. We believe that if the residents are not physically fit enough, we cannot expect their full contribution to society, though they may highly be regarded with knowledge and technology.
\end{abstract}

Keywords: NCD; Mekelle; Schools; Awareness

\section{Introduction}

Fitness is one of the key points for success in human life. Human can enjoy every moment with healthy life. There is correlation of progress of any nation with Number of its healthy citizens. Even, most of the developing and competitive nations prepared several policies targeting to get healthiest and fittest citizens by 2020 and so on. On the other hand unhealthy and less fit persons are not respected by the society and more over they are considered as a burden. An article written by "list land", mentioned that fat people are discriminated in different area, such as few airlines refused passengers due to their obese, parent take less interest on fatty kids, some of the universities will give less privilege to get admit for obese scholars, even gym centres charges extra money for obese people, more over obese kids are more likely to be bullied. Focusing on Ethiopia, a research and survey conducted by AstraZeneca Young Health Programme stated that as per the data collected between 2009 and 2014, it is found that Ethiopian youth are prone to four risk factors for non-communicable disease via overweight, tobacco usage, physical inactivity and alcohol usage. To counter these non-communicable diseases, nation needs time and huge amount of work force and financial aids. As per the African health observatory, Ethiopia Health workforce is very less. They reported that in Ethiopia two nurses and midwifery and 0.4 physician personnel are available in every 10,000 population.

Assefa, NCD Program Coordinator and Disease Prevention and Control Cluster Coordinator stated that non-communicable diseases (NCDs) accounted for 30\% of deaths in Ethiopia in 2014. The four major NCD's, namely cardiovascular diseases, cancers, diabetes and chronic respiratory diseases were responsible for more than $80 \%$ of NCD-related deaths. An estimated 3.3\% of adults use some form of tobacco, while the prevalence among very young adolescents (age group 13-15 years) is estimated to be much higher rate of $7.9 \%$; the figures vary region/ state wise, also. The survey estimated $9 \%$ of males and $25 \%$ of females, and $11 \%$ of rural and $20 \%$ of urban populations cover insufficient levels of physical activities. Whereas Ethiopia Fact sheet of Health Statistics-2010 (issued by WHO-Africa) states that $20 \%$ of diseases are due to non-communicable disease. This results $12 \%$ of death of NCD as pre-mature death. On listing non-communicable disease, it was noted that Neuropsychiatric conditions, Cardiovascular diseases, Respiratory diseases, Malignant neoplasm's, Digestive diseases, Endocrine disorders, Musculoskeletal diseases, Genitourinary diseases, Diabetes mellitus, Skin diseases, Oral conditions, Other neoplasm's have been recorded in Ethiopia. More over spending money over disease/disorder treatment is just like financial haemorrhage for development of nation. The Ethiopian government expenditure on health was $8.5 \%$ of total expenditure in 2000 , whereas it has been 
increased by $10.2 \%$ in 2007 [1]. This problem was highlighted on African Union Conference of Ministers of Health (CAMH6) Sixth Ordinary Session, which was organized at Addis Ababa, Ethiopia, during 22nd -26th April 2013. The theme of that conference was "The Impact of Non-Communicable Diseases (NCDs) and Neglected Tropical Diseases (NTDs) on Development in Africa", where all nations of Africa have discussed on risk factors, side-by-side, analysed that each nation have to face financial burden, which would be the cause of hindrance for nation's growth and development.

The seriousness of this issue has been discussed at both international as well as national levels, several times but still unclear about the awareness of such problem at grass-root level and that too among young generation. Thus the researchers are anxious enough to know the level of NCD problems and cause, among the young generation. The purpose of the study was to know the level of knowledge / awareness regarding Non-Communicable Disease and benefit of sports to promote health [2].

\section{Methodology}

\section{Tools for survey}

To start the survey, proper self-made 8 open ended questionnaires were prepared. The self-made questionnaires were revised by three different experts from Mekelle University. Moreover to make the question standardized with high value and reliability, the questions were re-evaluated by eight school teachers for more than three times. The questions were based on different enquiries about knowledge of non-communicable disease, its causes, and consequences on health, wealth, family along with preventive measures. Other than these, questions were also focused on utility of sports and its benefits for mental and physical health, wealth, fitness, socialization and the interest towards sports. The questions were prepared in simple English and were instructed to answer in either English language or in their vernacular and more over it was also instructed they could leave the question unanswered if feel uncomfortable to reply.

\section{Survey method}

Our survey target was high schools at Mekelle City, Tigray, Ethiopia. Thus, the research design was purely survey and the sample selection was simple random sampling. Thus the team members planned to select five high schools from different parts of Mekelle city, with different socio-economic background, to get varied amount of feedback to our self-made questionnaires. Thus we have selected five high schools ( 3 public and 2 private). To begin with, our team members approached to the officials and management of those five schools and took an appointment to explain the purpose of the survey. After convincing the officials and management of the schools our team members again approached to the school academic directors and senior school teachers and re-explained to them about the purpose of the survey and requested for the cooperation and kind coordination [3]. Based on the request, the academic director and school teachers allowed team members to have an interaction with the school students. We asked the teachers to get volunteer participants who can give the reply. Thus, we got heterogeneous mixture of voluntary participants.

\section{Program workout}

Before starting the program, we gave the brief information about the survey, and asked them to fill the forms. The forms were having two sections; the first section was on demographic information, the second section contains delight open ended questions. The questions were in English medium, and were instructed to fill the form with correct information. They were also apprised that, if they are unable to understand the questions they are free to ask to the researcher or school teacher [4]. If they are not willing to reply, they can leave the question as unanswered. They are not allowed to copy the answer. The questionnaires were given in comfortable zone decided by the teacher.

\section{Results}

As per our survey objectives we found interesting data, and the facts are enumerated in (Table 1) below:

\begin{tabular}{|l|l|l|l|l|l|l|}
\hline SI.No & School & \multicolumn{3}{l|}{ Boys participants } & \multicolumn{2}{l|}{$\begin{array}{l}\text { Girl's } \\
\text { participants }\end{array}$} \\
\hline & & $n$ & $\begin{array}{l}\text { Average } \\
\text { age }\end{array}$ & $n$ & $\begin{array}{l}\text { Average } \\
\text { age }\end{array}$ & $\mathrm{N}$ \\
\hline 1 & Public school-1 & 38 & 16.26 & 32 & 16.22 & 70 \\
\hline 2 & Public school-2 & 34 & 17.32 & 36 & 17.17 & 70 \\
\hline 3 & Public school-3 & 54 & 17.48 & 33 & 16.58 & 87 \\
\hline & Subtotal-1 & 126 & 17.06 & 101 & 16.68 & 227 \\
\hline 4 & Private school-1 & 42 & 15.88 & 21 & 16.9 & 63 \\
\hline 5 & Private school-2 & 41 & 16.26 & 25 & 15.88 & 66 \\
\hline & Subtotal-2 & 83 & 16.07 & 46 & 16.35 & 129 \\
\hline & $\begin{array}{l}\text { Grand total of all } \\
\text { five schools. }\end{array}$ & 209 & 16.88 & 147 & 16.57 & 356 \\
\hline
\end{tabular}

Table 1: Number of voluntary participants from five different schools.

In an overall from three public schools, 126 boys with average age of 17.06 years and 101 girls with average age 16.68 years and from two private school 83 boys with average age of 16.07 years and 46 girls, with an age of 16.35 years, were participated voluntarily in our survey program.

Before asking anything we tried to find out their mental status and we asked about how they are feeling today. Out of 147 girls, 8 of them said negative, such as bored, tensed, stressed, and unhappy, like on but on other side 9 out of 209 boys reported like sad, unhappy and bored to attend the survey [3-5]. Thus data shows assured us for correct feedback. Further, we tried to analyse the first part of the questionnaires, which is related to health knowledge issues. We asked four simple open-ended questions and got following response which is shown in (Table 2).

From the above table it is clear that overall the school students are less exposed towards health related issues. The students whoever responded are aware on communicable and infectious disease such as HIV/AIDS, psychological sickness, aces and pains at different part of body, congenital problems of heart and kidney, neurological problems like seizures, delayed psychological developmental and so on, which are general discussion in society. But as per our observations we have never heard the discussion on bad effect of alcohol, smoking and chat leave consumption. 
Citation: Mukherjee S, Hasrani SS, Saini RC (2016) Analysis on the Awareness of Non-Communicable Disorders and its Prevention through Sports and Fitness Program among High School Students of Mekelle. J Trop Dis 4: 216. doi:10.4172/2329-891X.1000216

Page 3 of 8

\begin{tabular}{|c|c|c|c|c|c|c|c|c|c|c|c|}
\hline \multicolumn{7}{|c|}{ Frequency of response from boys } & \multicolumn{5}{|c|}{ Frequency of response from girls } \\
\hline \multicolumn{2}{|l|}{ Questions? } & \multirow[t]{2}{*}{$\begin{array}{l}\text { What is health } \\
\text { problem }\end{array}$} & $\begin{array}{l}\text { What are the } \\
\text { causes of } \\
\text { health problem }\end{array}$ & \multicolumn{2}{|c|}{$\begin{array}{l}\text { Non- } \\
\text { communicab } \\
\text { le disease }\end{array}$} & \multirow[t]{2}{*}{$\begin{array}{l}\text { How do you } \\
\text { prevent } \\
\text { disease }\end{array}$} & \multicolumn{2}{|c|}{$\begin{array}{l}\text { What is health } \\
\text { problem }\end{array}$} & \multirow[t]{2}{*}{$\begin{array}{l}\text { What are the } \\
\text { causes of } \\
\text { health problem }\end{array}$} & \multirow[t]{2}{*}{\begin{tabular}{|l|} 
Non- \\
communicab \\
le disease
\end{tabular}} & \multirow[t]{2}{*}{$\begin{array}{l}\text { How do you } \\
\text { prevent disease }\end{array}$} \\
\hline Schools $\downarrow$ & $\mathrm{n}$ & & & & & & $\mathrm{n}$ & & & & \\
\hline Public school-1 & 38 & 3 & 0 & 1 & 3 & & 32 & 3 & 0 & 2 & 3 \\
\hline Public school-2 & 34 & 7 & 8 & 7 & 3 & & 36 & 4 & 4 & 9 & 2 \\
\hline Public school-3 & 54 & 9 & 5 & 7 & 5 & & 33 & 13 & 4 & 5 & 3 \\
\hline Public total & 126 & 19 & 13 & 15 & 11 & & 101 & 20 & 8 & 16 & 8 \\
\hline Public-percentile & & $15.07 \%$ & $10.31 \%$ & $11.9 \%$ & 8.7 & $3 \%$ & & $19.8 \%$ & $7.92 \%$ & $15.84 \%$ & $7.92 \%$ \\
\hline Private school-1 & 42 & 10 & 5 & 7 & 7 & & 21 & 4 & 1 & 5 & 2 \\
\hline Private school-2 & 41 & 6 & 3 & 3 & 1 & & 25 & 4 & 1 & 1 & 6 \\
\hline Private total- & 83 & 16 & 8 & 10 & 8 & & 46 & 8 & 2 & 6 & 8 \\
\hline Private percentile- & & $19.22 \%$ & $9.63 \%$ & $12.04 \%$ & 9.6 & $3 \%$ & & $17.39 \%$ & $\begin{array}{l}6.34 \% \\
\end{array}$ & $13.04 \%$ & $17.39 \%$ \\
\hline Grand Total & 209 & 35 & 21 & 25 & 19 & & 147 & 28 & 10 & 22 & 16 \\
\hline Percentile & & $16.74 \%$ & $10.04 \%$ & $11.96 \%$ & 9.0 & & & $19.04 \%$ & $6.80 \%$ & $14.96 \%$ & $10.88 \%$ \\
\hline
\end{tabular}

Table 2: Number of correct responses from high school students on health questionnaires.

From the above table it is clear that overall the school students are less exposed towards health related issues. The students whoever responded are aware on communicable and infectious disease such as HIV/AIDS, psychological sickness, aces and pains at different part of body, congenital problems of heart and kidney, neurological problems like seizures, delayed psychological developmental and so on, which are general discussion in society. But as per our observations we have never heard the discussion on bad effect of alcohol, smoking and chat leave consumption.

\section{Sports Benefits}

From our enquiry about the benefits of sports on health we got few perfect factual observations.

\begin{tabular}{|c|c|c|c|c|c|c|c|c|}
\hline & \multicolumn{4}{|c|}{ Boys } & \multicolumn{4}{|l|}{ Girls } \\
\hline & $\mathrm{n}$ & Health & Recreational & No-response & $\mathrm{n}$ & Health & Recreational & No-response \\
\hline Public school-1 & 38 & 16 & 1 & 21 & 32 & 20 & 3 & 9 \\
\hline Public school-2 & 34 & 8 & 22 & 4 & 36 & 6 & 18 & 12 \\
\hline Public school-3 & 54 & 35 & 18 & 1 & 33 & 10 & 20 & 3 \\
\hline Sub -total-1 & 126 & 59 & 41 & 26 & 101 & 36 & 41 & 24 \\
\hline Sub-Persentile-1 & & $46.82 \%$ & $32.53 \%$ & $20.63 \%$ & & 35.64 & $40.59 \%$ & $23.76 \%$ \\
\hline private school-1 & 42 & 22 & 19 & 1 & 21 & 7 & 12 & 2 \\
\hline private school-2 & 41 & 25 & 14 & 2 & 25 & 8 & 14 & 3 \\
\hline Sub Total-2 & 83 & 47 & 33 & 3 & 46 & 15 & 26 & 5 \\
\hline Sub Percentile -2 & & $56.62 \%$ & $39.75 \%$ & $3.61 \%$ & & $32.60 \%$ & $56.52 \%$ & $10.86 \%$ \\
\hline Grand Total & 209 & 106 & 74 & 29 & 147 & 51 & 67 & 29 \\
\hline Percentile & & $50.71 \%$ & $35.40 \%$ & $13.87 \%$ & & $34.69 \%$ & $45.57 \%$ & $19.72 \%$ \\
\hline
\end{tabular}

Table 3: The response of the students on sports benefits. 
Citation: Mukherjee S, Hasrani SS, Saini RC (2016) Analysis on the Awareness of Non-Communicable Disorders and its Prevention through Sports and Fitness Program among High School Students of Mekelle. J Trop Dis 4: 216. doi:10.4172/2329-891X.1000216

Page 4 of 8

We tried to analyse the reasons for playing sports games, as an open ended question which is shown in (Table 3). On analysing the answers we classified them into three different categories, via health categorywhere the answers are related to health benefits, fitness, and prevention from certain disease, anti-stress therapy. The second category is recreational such as entertainment, enjoyment, interest and other nonhealth issues. The third category is of non-response or no ideas why they play games. Above Table states that only, $50.71 \%$ of boys know benefits of sports on health and fitness where as $45.57 \%$ of girls know the utility of sports only as source of recreation and entertainment [6]. Very surprisingly $13.87 \%$ of boys and $19.72 \%$ of girls don't know or not responded as why they play sports and games.

\section{Effects When Un-engaged in Sports}

This was also an open ended question. We are successful to classify the answers into three different categories. The first category is effect of physical conditions such as illness, not well, fat, over-weight, weight gain, disease and so on. The second category was reflecting on psychological factors, such as boring, sad, anger, stress, anxiety, not happy, depressed and so on and the third category was with no response to the question and the result is listed in (Table 4).

\begin{tabular}{|c|c|c|c|c|c|c|c|c|}
\hline & \multicolumn{4}{|c|}{ Boys } & \multicolumn{4}{|l|}{ Girls } \\
\hline & $\mathrm{n}$ & $\begin{array}{l}\text { Effect } \\
\text { Physical on } \\
\text { condition }\end{array}$ & $\begin{array}{l}\text { Effect on Psychological } \\
\text { condition }\end{array}$ & No-response & $\mathrm{n}$ & $\begin{array}{l}\text { Effect on } \\
\text { Physical } \\
\text { condition }\end{array}$ & $\begin{array}{l}\text { Effect on Psychological } \\
\text { condition }\end{array}$ & No-response \\
\hline Public school-1 & 38 & 8 & 9 & 21 & 32 & 9 & 4 & 19 \\
\hline Public school-2 & 34 & 4 & 12 & 18 & 36 & 3 & 4 & 29 \\
\hline Public school-3 & 54 & 15 & 16 & 23 & 33 & 4 & 12 & 17 \\
\hline Sub -total-1 & 126 & 28 & 37 & 62 & 101 & 16 & 20 & 65 \\
\hline Sub-Persentile-1 & & $22.22 \%$ & $29.36 \%$ & $49.2 \%$ & & $15.81 \%$ & $19.8 \%$ & $64.35 \%$ \\
\hline private school-1 & 42 & 23 & 15 & 4 & 21 & 14 & 4 & 3 \\
\hline private school-2 & 41 & 28 & 5 & 8 & 25 & 17 & 1 & 7 \\
\hline Sub -Total-2 & 83 & 51 & 20 & 12 & 46 & 31 & 5 & 10 \\
\hline Sub Percentile -2 & & $61.45 \%$ & $24.09 \%$ & $14.45 \%$ & & $67.39 \%$ & $10.87 \%$ & $21.74 \%$ \\
\hline Grand Total & 209 & 79 & 57 & 74 & 147 & 47 & 25 & 75 \\
\hline Percentile & & $37.8 \%$ & $27.27 \%$ & $35.4 \%$ & & $31.97 \%$ & $17 \%$ & $51.02 \%$ \\
\hline
\end{tabular}

Table 4: Students view, on not engaging physical activity/sports.

From the above table, it is clear that $51.02 \%$ girls are not aware of disadvantages of sports and games, at all; similarly one third of boys are also sitting in the same boat. On comparing public versus private schools, a marked difference has been observed. Among public school children, $64.35 \%$ girls and $49.2 \%$ boys are unaware of bad effect of non-playing sports as compare to private schools where only $21.7 \%$ girls and $14.15 \%$ boys are unaware to the bad effects of not playing sports.

\section{Leisure Time Activities}

To analyse their involvement practically in physical activities we asked the open ended questions about their activities on leisure time. When we enquired about the benefits of being involved in sports and games it is interesting to note that while majority of the boys expressed it as beneficial for health whereas the girls consider sports as recreational activities only. On reverse of the above question we tried to enquire as negative consequences if not involved in the sports, surprisingly majority of the students don't have any ideas or even they haven't thought it before. It is a known fact that physical activities are one of the best, ideal and economical remedial measure as well preventive therapies for most of the disease and/or disorder come under non-communicable health problems. So we tried to find out the activities they prefer during leisure time. To our surprise it is seen that $51.2 \%$ boys and $68.7 \%$ girls of 16 years group prefer to spend time in non-physical activities. As we know that enquiry was open ended, we got several and different type of answers. According to their answer our experts categorized them into active group and non-active group which are shown in (Table 5).

\begin{tabular}{|l|l|l|l|l|l|l|}
\hline & & & Boys & & & Girls \\
\hline & $\mathrm{n}$ & Active & $\begin{array}{l}\text { Non- } \\
\text { active }\end{array}$ & $\mathrm{N}$ & Active & Non-Active \\
\hline Public school-1 & 38 & 24 & 14 & 32 & 20 & 12 \\
\hline Public school-2 & 34 & 9 & 25 & 36 & 7 & 29 \\
\hline Public school-3 & 54 & 31 & 23 & 33 & 11 & 22 \\
\hline Sub- total-1 & 126 & 64 & 62 & 101 & 38 & 63 \\
\hline $\begin{array}{l}\text { Sub- } \\
\text { Persentile-1 }\end{array}$ & & $50.79 \%$ & $49.2 \%$ & & $37.62 \%$ & $62.38 \%$ \\
\hline private school-1 & 42 & 21 & 21 & 21 & 4 & 17 \\
\hline
\end{tabular}


Page 5 of 8

\begin{tabular}{|l|l|l|l|l|l|l|}
\hline private school-2 & 41 & 17 & 24 & 25 & 4 & 21 \\
\hline Sub Total-2 & 83 & 38 & 45 & 46 & 8 & 38 \\
\hline $\begin{array}{l}\text { Sub Percentile } \\
-2\end{array}$ & & $45.78 \%$ & $54.21 \%$ & & $17.39 \%$ & $82.6 \%$ \\
\hline Grand Total & 209 & 102 & 107 & 147 & 46 & 101 \\
\hline Percentile & & $48.8 \%$ & $51.2 \%$ & & $31.29 \%$ & $68.7 \%$ \\
\hline
\end{tabular}

\section{Games Preference}

Answers on the preference of games we divided them into indoor games, outdoor games, and not interested in any kind of games or didn't respond to the questions the estimated data is shown in (Table 6). Among indoor games we have compiled the responses such as videogames, chess, playing inside house, recreational dance and traditional indoor games and so on, whereas in outdoor games category we have compiled responses such as football, cycling, basketball, hand ball, professional dance and such activities.

Table 5: Indicates that during leisure time, $49.2 \%$ of public school boys and $62.38 \%$ girls are involve in non-active work, whereas in private school kids $54 \%$ boys and $82.6 \%$ girls are involved in non-active activities.

\begin{tabular}{|c|c|c|c|c|c|c|c|c|}
\hline & & & Boys & & & & Girls & \\
\hline & $\mathrm{n}$ & Indoor & Outdoor & Not interested & $\mathrm{n}$ & Indoor & Out door & Not interested \\
\hline Public school-1 & 38 & 10 & 25 & 3 & 32 & 12 & 18 & 2 \\
\hline Public school-2 & 34 & 7 & 14 & 13 & 36 & 12 & 19 & 5 \\
\hline Public school-3 & 54 & 12 & 37 & 5 & 33 & 8 & 18 & 7 \\
\hline Sub- total-1 & 126 & 29 & 76 & 21 & 101 & 32 & 55 & 14 \\
\hline Sub-Persentile-1 & & $23.02 \%$ & $60.32 \%$ & $16.67 \%$ & & $31.68 \%$ & $54.45 \%$ & $13.86 \%$ \\
\hline private school-1 & 42 & 2 & 39 & 1 & 21 & 4 & 7 & 10 \\
\hline private school-2 & 41 & 6 & 16 & 19 & 25 & 8 & 9 & 8 \\
\hline Sub Total-2 & 83 & 8 & 55 & 20 & 46 & 12 & 16 & 18 \\
\hline Sub Percentile -2 & & $9.63 \%$ & $66.26 \%$ & $20.09 \%$ & & $26.08 \%$ & $34.78 \%$ & $39.13 \%$ \\
\hline Grand Total & 209 & 37 & 131 & 41 & 147 & 44 & 71 & 32 \\
\hline Percentile & & $17.7 \%$ & $62.67 \%$ & $19.61 \%$ & & $29.39 \%$ & $48.3 \%$ & $21.77 \%$ \\
\hline
\end{tabular}

Table 6: Preference of games divided into indoor games, outdoor games and not interested.

\section{Discussions}

It is well accepted fact that sports is one of the most lovable recreational activities and now days the benefits of the sports are on exploration. WHO defined Health is a state of complete physical, mental and social well-being and not merely the absence of disease or infirmity. On the other side when we discuss on disease [7] mentioned that disease broadly refers to any condition that impairs the normal functioning of the body which associated with dysfunctioning of the body's normal homeostatic process and caused by pathogens. Depending on etiology the disease are classified into several categories, which ranges from genetic and hereditary problem to age related problems. It also depends on mode of spreading, such as communicable to non-communicable. Also it depends on source of problems such as environmental factors, life style, life stress, job hazards and so on. Depending on disease's nature, it may affect single organ to multi organ problem, the disease may be local or it may spread from one part to the other part of the body such as cancer, infection and so on but exactly it has been classified by WHO in International Classification of Diseases, Tenth Revision, Clinical Modification (ICD-10-CM). But for the research survey we focused on non- communicable disease. According to World Health Organization; non-communicable diseases also known as chronic diseases- which don't passes from person to person. They are of long duration and generally they have slow progression. According to the organization the non-communicable diseases are cardiovascular diseases (like heart attacks and stroke), cancers, chronic respiratory diseases (such as chronic obstructed pulmonary disease and asthma) and diabetes. According to recent statistics it states that, in developing countries, the non-communicable disease (NCD) and risk factor are burdens for the nation, as treating such diseases can be expensive. In developing countries where health care costs are much generally borne by patients themselves, and thus who live in poverty leads to further severe poverty.

Most of the nations of African Continent are known for underdevelopment and few of them are categorized as developing nation. According to United Nations Committee for Development Policy (May 2016) Ethiopia has been categorized in the list of developing nation. According to WHO Africa it is a well-known fact that $30 \%$ of the deaths are due to non-communicable disease and that too, premature. To fight back this problem the Govt. of Ethiopia is spending more than $5 \%$ of annual budget for taking care of such problems. The main sources of the problem are alcohol, chat leaves, road traffic injuries and due to fast development and modernization the white collar jobs. 
These jobs are on high craze and as a result, due to less physical activity the overweight are on high stake. In 2016 study it states that African report news agency's reporter and Ministry of health and ministry of industry stated that every year there is a annual growth of $25 \%$ of pharmaceuticals industries and further their will be $14 \%$ increment up to 2018. Even industries of Pharmaceutical are increasing day by day whose many medical drugs are related to anti-hypertension antidiabetic, drugs related to recheck the thyroid hormones and so on (List of essential medicine for Ethiopia-2010). Though we appreciate that the health development and facilities are growing but in the similar way the sedentary life style modification related problems are also in higher side. Many of the Addis Ababa private clinics are clear evidence to see the raise cases of hypertension day by day [8].

Considering the above facts the researcher's main objective was to find the level of awareness about non communicable disease among school students. To analyse our objectives we went to five schools randomly and visited to the kids those who were volunteer to participate in our study. A similar study has been done on 375 kids where their aim is to assess the awareness of school children regarding the risk factors of non-communicable diseases and another similar study was done on 588 kids. They participated on the assessment of awareness NCD and their risk factors among rural intermediate school children of Varanasi, India. Prior to have a discussion with school kids, we had taken permission from school management, teachers and other instructors. We took care that their routine class hours and study should not be disturbed. We gave open ended questionnaires to all students and asked them to fill it within a limited time and if they are unwilling to reply they can leave the question. It was also instructed not to copy from their friends answer book and they should write to the best of their true knowledge. For our research 357 volunteer students (209 boys and 147 girls) participated and their average age was 16.7 years ( 16.85 years for boys and 16.57 years for girls).

During questionnaires formation we planned to know about the exposure on alcoholic, smoking or related agents or any experiences thereof, which are non-communicable disease. But as the local schools teachers asked to remove such question as the society prohibits to take any such substance if (s)he is under eighteen years. The arguments given by the teachers were quite reasonable, as we have never observed consuming of alcohol in any public/private pubs or restaurant by the minors nor we have observed in any cultural and traditional ceremony. Even teachers replied that these section students will not answer as everyone is aware of it as a socially prohibited act [9]. Though, it was important to us as it states that risk factors for NCD knowledge are very less among adolescent. According to their research they shared an important report that only one tenth of students were aware that alcohol and sedentary life is one of the causes of NCD such as Diabetics.

Thus to analyses their knowledge we asked open questions like what they understand by health problem? What are the causes of health problems? What ideas they have on Non-communicable disease? And, How to prevent from such problems? On the other section of the questionnaires we tried to know what is the reason that one should participate in sports and games and the consequences if one does not participate in sports and games. The data what we received is really astonishing and it is beyond our expectation [10,11]. While enquiring about their ideas on health problem only $16.74 \%$ boys and $19.04 \%$ girls have the exact idea and while enquiring about the etiological factors $10.04 \%$ boys and $6.08 \%$ girls know about. It's strange to notice that private school boys (19.22\%) have better ideas then than their counterparts of public school boys (15.07\%) but in case of girls it is reverse, i.e., public school girls (19.8\%) have better understanding then than private school girls (17.39\%). On enquiring about the causes of the problem, $10.31 \%$ of boys have better understanding, than girls. Total $6.8 \%$ girl's replied of whom $7.92 \%$ from public school and $4.34 \%$ from private school. Our team believes that most probably the kids are aware of sexual transmitted disease and its causes, where boys are able to express but girls felt shy to reveal the answer. When we asked about non-communicable problems, it is interesting to know that girls (14.96\%) have better idea than boys $(11.96 \%)$, and about the knowledge preventive method of girls $(10.88 \%)$ have better concept then boys (9.09\%).

The object of second section was to know about the benefits of sports for health. Steven Allender stated one of his reviewed article that "physical activity give benefits to psychosocial health, functional ability and general quality of life and has been proven to reduce the risk Non communicable disease such as coronary heart disease and few types of cancers and helps energy expenditure' and reduce obesity like disorder. Whereas physical inactivity include obesity, hypertension, diabetes, back pain, poor joint mobility and psychosocial problems".

On this issue we asked about the reasons for playing sports and games. We got mixed and interesting result. We found that $50.71 \%$ of boys consider it beneficial as it has good effect on health, whereas $45.57 \%$ of girls recognize sports as for entertainment only. But thing issue for which the researchers are still puzzled that in public schools $20.63 \%$ of boys and $23.76 \%$ of girls didn't respond as why to participate in sports and games, or what is the benefit of sports and games. As compared to public school, the private school students are smarter enough, but still it's unclear that why $13.87 \%$ of boys and $19.72 \%$ of girls don't have any idea as to why they are playing or what is the benefit if they participate in sports [12].

On the reverse side when we enquired about the disadvantages of not to participate the sports and games, we understand that received data in very curious. About $37.8 \%$ boys believe that sports affects physical condition, $27.27 \%$ believe that it will affect psychological condition and remaining $35.4 \%$ believe that there is no side effect if not playing sports and games, whereas $51.02 \%$ girls believe that there is no bad consequences for not involving in sports and games. On reviewing the data in more details we found that public schools students are more unaware of bad consequences of not playing sports and games. On comparing, $49.2 \%$ of boys and $64.35 \%$ girls of public schools don't have any idea about the bad consequences of not involving in sports. On the other hand $61.45 \%$ of boys and $67.39 \%$ of girls from private schools believed that its will affect physical health.

In the next phase of questionnaires we tried to find out the school students interest in physical activities. We asked two opened ended questions regarding their activities in leisure time and preferred sports activities. On analysing the interested or preferred activities of the students it has been divided in to physically active or non-active. The data reveals that $51.2 \%$ boys and $68.7 \%$ girls prefers to spend their leisure time in physically non-active activities. Which we hope is a warning sign of health challenge for coming generation of Ethiopia. Moreover, it will affect mainly middle and high income group families, because our data revels that $54.21 \%$ of boys and $82.6 \%$ of girls belong to private schools, and mainly private school students belong to rich or at least middle income group families [13-15]. Our result showed an excellent correlation with the reasoning that showed that the transition from childhood to adulthood was a key risk time for drop-outs, from sports. Generally teenagers did not wish to be associated with activities 
which they described as 'childish' and instead chose activities that were independent and conferred a more adult identity upon them. One of the participant described in their study, leaving a netball team of younger girls because it was 'babyish'. A number of young women interviewed by these researchers described their belief that 'adult' women did not participate in physical activity or sport. Moreover it is also found similar result and concluded that female, in private schools and in the 8th to 9th grade were factors associated with lower levels of physical activity whereas younger school children and those from low economic classes spent less time engaged in sedentary activities. To confirm the above result we asked about the games or sports they preferred, according to their preference we categorized them into indoor games, outdoor games and not interested in games. It was comforting to see that $62.67 \%$ boys are interested to play out-door games while $48.3 \%$ girls have shown their interest in out-door games. Though, the responses from public schools students are good for outdoor games $(60.32 \%$ boys and $54.45 \%$ girls) as well for private school boys (66.26\%), but it is really equally disappointing to us that $26.08 \%$ of girls prefer to play indoor games and $39.13 \%$ of girls from private schools are not interested towards any kind of sports and games. The reason can vary as [16] found that the negative experiences during school physical activity were the strongest factor discouraging participation in teenage girls [17]. Cockburn and Clarke [16] reported as many girls give priority to impressing boyfriends and other peers than physical activity. While most of the girls have their priorities to appear feminine and attractive rather sweaty muscular image active women [17]. We believe this may be a cause for Mekellian school students.

\section{Conclusions}

By observing all pros- and cons- of data what we received from our pilot research survey, we believe that knowledge towards health problems and related health issues are at infancy stage. Moreover, the students of Mekelle high schools have ignorance towards the causes of disease and other health problems, thus this may be one of cause of having unhygienic habits and leads to several kinds of infections as well as non-infectious diseases, also. The students who expressed their knowledge about diseases, they only were aware about mental health problem or sexual transmitted disease such as HIV/AIDS, syphilis and so on. But when we asked about the causes and remedial factors most of the girls didn't expressed and might felt shy on it. About noncommunicable disease very few students have any idea about it, but somehow girls have better idea than the boys. More over girls expressed good ideas to prevent such problem like prohibition of alcohol, smoking, chat leaves and so on and focused on organic diet and continental dishes. When we enquired about the benefits of being involved in sports and games it is interesting to note that while majority of the boys expressed it as beneficial for health whereas the girls consider sports as recreational activities only. On reverse of the above question we tried to enquire as negative consequences if not involved in the sports, surprisingly majority of the students don't have any ideas or even they haven't thought it before. It is a known fact that physical activities are one of the best, ideal and economical remedial measure as well preventive therapies for most of the disease and/or disorder come under non-communicable health problems. So we tried to find out the activities they prefer during leisure time. To our surprise it is seen that $51.2 \%$ boys and $68.7 \%$ girls of 16 years group prefer to spend time in non-physical activities. And it's very surprising that $82.6 \%$ girls prefer to remain physically non active. As per our opinion if this data matches with the rest of Ethiopian schools; soon this country will face big challenge, especially by upcoming young generation on their health. Interestingly towards sports and games though boys are quite interested towards out -door games such as football, but still $21.77 \%$ girls and $19.61 \%$ boys are not interested in sports or such physical activities, i.e., 1 in every five individual is out of interest towards sports, which is not at all a good sign for upcoming Ethiopian sports and games as well for public health.

\section{Recommendations}

Our survey report is a warning bell to Ethiopian public health authority and Ethiopian sports authority that there is lack of knowledge among young generation on non-communicable disease, its causes and prevention. Similarly youth have very little knowledge about the benefits of physical activities and consequences thereof. We would like to recommend that schools should make aware their pupil of such problems as STD's by inviting different medical professionals. Sports teachers should take it as a very serious challenge, for popularizing and upgrading the physical education. The school authority should not consider sports only as a recreational subject but should take seriously as other main subjects such as natural sciences. Moreover sports should be utilized as a prophylactic and booster dosage for growth and development of adolescent students in terms of physical, physiological, psychological, and social and all round development.

\section{Acknowledgements}

Thanks to Dept. of sports sciences, for moral and physical support, RandCS team CNCS for financial assistance, ICT-MU for providing internet support and to all academic and non-academic staff of Mekelle University.

\section{References}

1. Atlas of Health Statistics (2012) WHO AFRO.

2. Zeneca A (2015) Young Health Programme (YHP) Risk Factors Among Young People In Africa (Non-communicable Diseases).

3. World Health Report (2013) Research For Universal Health Coverage.

4. Atlas of Health Statistics (2010) WHO AFRO.

5. NCD Program Coordinator and Disease Prevention and Control Cluster Coordinator.

6. United Nations Committee for Development Policy (2016) Development Policy and Analysis Department of Economic and Social Affairs.

7. Buckley JM (2003) Oswego City School District Regents Exam Prep Centre.

8. International Classification of Diseases. Clinical Modification. National Centre for Health Statistics.

9. Elias MT (2016) The Africa report Pharmaceuticals. Pills for the Ethiopian populace.

10. National strategy and plan of action for pharmaceutical manufacturing development in Ethiopia (2015-2025) Developing the pharmaceutical industry and improving access. Federal Democratic Republic of Ethiopia Ministry of Health and Ministry of Industry.

11. List Of Essential Medicines For Ethiopia Food Medicine and Healthcare Administration and Control Authority of Ethiopia (2010).

12. Divakaran B, Muttapilly MJ, Sreedharan J, Shalini K (2010) Lifestyle risk factors of non-communicable diseases awareness among school children. Indian J Cancer 1: 9-13.

13. Siddharudha S, Manoj KG, Mohaptra A, Srivastava RK (2012) Awareness Of Non Communicable Diseases And Their Risk Factors Among Rural School Children. Indian Journal of Community health Volume 24. 
Citation: Mukherjee S, Hasrani SS, Saini RC (2016) Analysis on the Awareness of Non-Communicable Disorders and its Prevention through Sports and Fitness Program among High School Students of Mekelle. J Trop Dis 4: 216. doi:10.4172/2329-891X.1000216

Page 8 of 8

14. Allender S, Cowburn G, Foster C (2006) Understanding participation in sport and physical activity among children and adults a review of qualitative studies. Health Education Research 21: 826-835.

15. Coakley J, White A (1992) Making decisions gender and sport participation among British adolescents. Social Sport 9: 20-35.

16. Cockburn C, Clarke G (2002) Everybody's looking at you. Girls negotiating the "femininity deficit" they incur in physical education. 25: 651-665.
17. Oliveira TC, Moura AA, Cristiane S, Nunes J, Josenilde S, et al.(2010) Physical activity and sedentary lifestyle among children from private and public schools in Northern Brazil 44:6. 